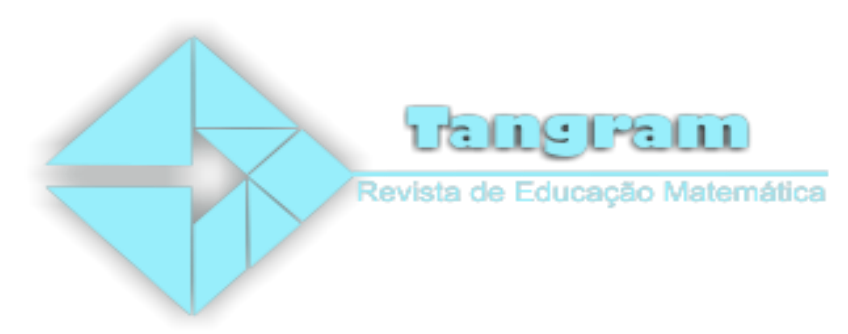

\title{
Funções Quadráticas com o auxílio do software Winplot
}

\section{Quadratic Functions with the help of Winplot software}

\author{
Paulo Jorge Magalhães Teixeira ${ }^{1}$
}

\begin{abstract}
Resumo: Este trabalho tem o propósito de apresentar resultados de um estudo feito com um grupo de 4(quatro) sujeitos: 2(dois) professores da educação básica e 2(dois) alunos da $1^{\text {a }}$ série do ensino médio. O objetivo principal, utilizando comandos do software Winplot, foi de desenhar alguns tipos de funções quadráticas e promover procedimentos para resolver inequações do $2^{\circ}$ grau a partir do conhecimento do gráfico da função $\mathrm{f}(\mathrm{x})=\mathrm{x}^{2}$; verificar a aplicabilidade do software, com o seu uso, no sentido de avaliar possibilidades de utilizá-lo para o ensino desse conteúdo, com alunos da educação básica. A metodologia Design Experiments in Educational Research foi escolhida, por conta de ela possibilitar mudanças no desenho original da proposta. Valemo-nos de Shulman (1986), acerca dos conhecimentos dos professores no tocante à docência. Embora as atividades tenham contemplado parte do conteúdo sugerido para ser apresentado na Educação Básica, em relação ao que foi abordado os resultados mostraram-se promissores.
\end{abstract}

Palavras-chave: Funções Quadráticas. Software Winplot. Ensino.

Abstract: This paper aims to present results of a study done with a group of 4 (four) subjects: 2 teachers of basic education and 2(two) teachers of basic education and 2(two) students of the 1 st high school. The main objective, using procedures from the Winplot software, was to draw some types of quadratic functions and to promote procedures for solving 2nd degree inequalities from the knowledge of the graph of the function $\mathrm{f}(\mathrm{x})=\mathrm{x}^{2}$; to verify the applicability of the software, with its use in the sense of evaluating possibilities of using it to teach this contente, with students of basic education. The Design Experiments in Educational Research methodology was chosen, because it allows changes in the original design of the proposal. We are talking about Shulman(1986) about teachers' knowledge of teaching. Although the activities included part of the contente suggested to be presented in Basic Eduction, in relation to what was addressed the results showed to be promising.

Keywords: Quadratic Functions. Winplot Software. Teaching.

${ }^{1}$ Doutor em Educação Matemática, paulojorge@id.uff.br

Tangram - Revista de Educação Matemática, Dourados - MS - v.2 n.4, pp. 58-78 (2019) 


\section{Funções Quadráticas com o auxílio do software Wimplot}

\section{Motivação}

Brasil afora, não cabe mais constatar que ainda há aulas de matemática sendo apresentadas por meio da apresentação do conteúdo pelo professor unicamente no quadro branco (ou de giz) e o uso conjunto do livro didático.

Via de regra os alunos copiam o conteúdo que foi explicado e escrito pelo professor - possivelmente, pensado apenas por ele sem o convite aos alunos para que pensassem a respeito e juntos refletissem, questionassem, indagassem. Em seguida, o professor convida os alunos a resolverem exercícios do livro didático via imitação ou reprodução de procedimentos apresentados no livro e/ou feitos pelo professor. Quando muito, o professor faz uso de fichas de atividades preparadas por ele, as quais permitem que o aluno construa conhecimentos e se aproprie de conceitos acerca do conteúdo que está sendo ensinado.

Mas mesmo para essa possibilidade, há que considerar que os alunos tenham recebido o livro didático em tempo hábil, no início do ano letivo, como se espera, e o desenvolvimento da programação didática para aquele ano/série esteja em consonância com os conteúdos apresentados no livro. Quando seja possível que tal possibilidade ocorra - mesmo que não possa ser considerada ideal - já é um bom caminho percorrido para se alcançar o propósito de oferecer ensino básico de qualidade aos estudantes, pois não basta apenas que os alunos estejam matriculados nas escolas, mas lhes sejam oferecidas boas condições para estudarem e avançarem nos seus conhecimentos oferecendo, por exemplo: biblioteca, salas multiuso: vídeos, jogos, uso de material concreto, material manipulável, alimentação, orientação pedagógica, e outros.

É preciso avançar, pois tudo o que se alcançou até agora ainda é muito pouco diante de um voo maior quando se tem o propósito de obter saltos quantitativos e qualitativos consideráveis, e necessários, no tocante à uma educação de qualidade desejável alcançar.

Há que haver um esforço conjunto de professores, educadores, a escola, os governantes e a sociedade de modo a procurar alternativas mais atraentes ao aprendizado que pode/deve ser oferecido aos alunos da Educação Básica.

Alternativas educacionais que tenham como indispensável propósito o de oportunizar aos estudantes a apropriação de conhecimentos e competências - suficientes para que eles possam enfrentar com desenvoltura e diligência os desafios que, tanto a escola quanto a sociedade, saberão propor para resolverem, com certeza. Todas elas consoante a preparação que esperariam tivessem os estudantes alcançado ao longo da trajetória na Escola Básica.

Tangram - Revista de Educação Matemática, Dourados - MS - v.2 n.4, pp. 58 - 78 (2019) 


\section{Funções Quadráticas com o auxílio do software Wimplot}

Alternativas atraentes, que contemplem em suas bases a participação efetiva e lúdica dos alunos nos processos de construção de conhecimentos, habilidades e competências próprias a um ensino e a uma aprendizagem atraentes, propositivos e efetivos.

$\mathrm{E}$, não apenas no tocante às atividades que sejam pensadas e apresentadas pelo professor para serem resolvidas pelos estudantes na escola, mas também atividades que contemplem situações reais (ou adaptadas) presentes no cotidiano das suas famílias e da cidade em que vivem - ao alcance dos conhecimentos que eles têm e/ou que se esperaria tivessem. É nesse framework que se insere a proposta de trabalho objeto deste artigo.

Com a presença maciça da informática em todos os setores da comunicação, nos dias de hoje, torna-se imprescindível que a sala de aula disponibilize e promova o uso de recursos tecnológicos que favoreçam uma aprendizagem participativa, atuante e efetiva tanto por parte dos professores quanto dos alunos, vez que ainda é tímida a sua utilização nas escolas.

É bastante interessante e promissor o desenvolvimento que alguns conteúdos da Matemática básica podem alcançar com o auxílio de novas tecnologias (softwares e aplicativos), os quais permitem aos professores trazerem para a sala de aula novas concepções acerca de como é possível oportunizar ensino e aprendizagem de qualidade aos estudantes da Educação Básica. Dentre estes conteúdos situa-se o estudo das funções quadráticas com o apoio do software Winplot (programa computacional simples e gratuito), vez que é uma ferramenta que ajuda neste trabalho, como será visto em prosseguimento.

\section{Introdução}

As Tecnologias de Informação e Comunicação (TICs), em especial particular a tecnologia informática, podem ser excelentes aliados do professor em sala de aula (ou fora dela) e se tornarem valiosos recursos didáticos desde que adequada e prioritariamente sejam selecionadas e utilizadas para o particular momento da aprendizagem.

Sua utilização efetiva no ensino da Matemática tem o propósito de ampliar o campo conceitual do conteúdo em questão, mas também pode ser desenvolvido para confirmar resultados obtidos com papel e lápis, por exemplo.

Para a docência do professor que ensina Matemática na Educação Básica consideram-se habilidades desejáveis a todo professor, e a qualquer tempo, a familiarização e a utilização do computador para atividades com softwares educacionais (e da internet) como instrumento valioso de pesquisa, e como efetivo recurso didático.

Tangram - Revista de Educação Matemática, Dourados - MS - v.2 n.4, pp. 58 - 78 (2019) 


\section{Funções Quadráticas com o auxílio do software Wimplot}

Ademais, as atividades com softwares educacionais podem/devem ser apropriadas e desenvolvidas pelo professor, independentemente da área de atuação e do nível de ensino ou treinamento a que se propõe. Todavia, entretanto, o uso de recursos computacionais em sala de aula requer alguns cuidados, tais como, o conhecimento em profundidade dos recursos disponibilizados pelo software a ser trabalhado e o adequado planejamento do desenvolvimento das atividades no decorrer das aulas. Tais cuidados fazem-se necessários para permitir aos usuários a correta utilização dos recursos que um software permite utilizar, de forma gradual, compatível com o desenvolvimento das etapas de aprendizagem, permitindo que o estudante/usuário alcance a contextualização do conteúdo explorado - a ampliação conceitual - em diferentes campos de atuação e do conhecimento. Segundo Kenski (2007, p.5), as “TICs são suportes midiáticos populares, com enorme penetração social, baseados no uso das linguagens oral e escrita, e da síntese entre som, imagem e movimento".

Para fomentar os processos de ensino e de aprendizagem de conteúdos, em Matemática, as mídias digitais e a tecnologia informática podem oferecer grandes contribuições na medida em que:

- Reforçam o papel da linguagem gráfica, e de novas formas de representação;

- Permitem criar um ambiente interativo, que propicie a construção de conceitos, e

- Permitem a manipulação simbólica.

\section{As tecnologias digitais na formação e na ação do professor}

O mundo está em constante transformação, o que afeta, de modo especial e importante, os novos caminhos a serem trilhados para a área da Educação.

Nessa perspectiva o uso do computador na Educação Matemática, para Cláudio e Cunha (2001, p.68), “deve ser a essência do conhecimento efetivo numa sociedade baseada na informação", e na qual se assegure que os processos de ensino e de aprendizagem da Matemática não se restringem a um pequeno grupo de problemas ideais mas, também, a diferentes situações reais, notadamente as presentes no cotidiano dos estudantes e famílias.

Resultados de pesquisas pontuam que para obter resultados satisfatórios nos processos de ensino e de aprendizagem da Matemática é preciso despertar o interesse dos alunos no sentido de que eles tentem entender o que está sendo trabalhado (desenvolvido, proposto); que reflitam acerca do que é pedido que façam, e sobre o que estão fazendo, de Tangram - Revista de Educação Matemática, Dourados - MS - v.2 n.4, pp. 58 - 78 (2019) 


\section{Funções Quadráticas com o auxílio do software Wimplot}

modo a oportunizar condições para que pesquisem com curiosidade e determinação acerca da temática em questão, de modo a desenvolver o raciocínio crítico; a capacidade de argumentação, e a aquisição de habilidades e competências que os levem a ampliar os conhecimentos históricos, teóricos e práticos relativos ao conteúdo abordado.

De certa forma devem ser repensados os mecanismos e conhecimentos necessários aos que utilizam/irão utilizar o computador em sua prática pedagógica, por todos os envolvidos em Educação. Em particular, os que estão diretamente imbricados com a formação de professores de Matemática e os professores em serviço. À essa questão, assim refere Almeida (2000, p.110):

A formação desse professor em tecnologias informáticas deve ser um processo que o prepare para incitar seus educandos a: aprender a aprender; ter autonomia para solucionar as informações pertinentes à sua ação; refletir sobre uma situação-problema e escolher a alternativa adequada de atuação para resolvê-la; refletir sobre os resultados obtidos e depurar seus procedimentos, reformulando suas ações; buscar compreender os conceitos envolvidos ou levantar hipóteses. (Almeida, 2000, p. 110).

Portanto faz-se necessário que durante a formação do professor, inicial ou continuada, este profissional seja levado a refletir a respeito das diferentes concepções sobre o uso do computador durante os processos de ensino e de aprendizagem, como transmissor de conhecimentos ou como ferramenta auxiliar do aluno na construção do seu próprio conhecimento. Também devem ser analisados pelo professor, em serviço, os limites e as potencialidades de seu uso para que, assim, ele possa tomar decisões em relação às diferentes formas e objetivos que precisa estabelecer de modo a utilizar essa importante tecnologia para o melhor desenvolvimento dos processos de ensino e de aprendizagem - razão maior de suas preocupações enquanto educador. Se um professor de Matemática optar por utilizar a máquina - o computador - para transmitir conhecimentos, o computador simplesmente tornar-se-á tal como um caderno mais prático, pronto, acabado, com anotações que não contemplam os possíveis erros como um instrumento de aprendizagem ou um quadro de giz (ou branco), mais moderno e de visual atraente, que dispensa as reações e a atenção dos atores envolvidos no processo, quais sejam: alunos e professor. No entender de Valente (1995, p.12), o aluno seria apenas "um virador de páginas eletrônicas".

A segunda opção, é o professor de Matemática tornar o uso do computador como um novo ambiente, um facilitador da aprendizagem, permitindo ao aluno compreender que no contexto digital mudam as formas de pensar, de agir, de fazer, de corrigir e de aprender. Tangram - Revista de Educação Matemática, Dourados - MS - v.2 n.4, pp. 58 - 78 (2019) 


\section{Funções Quadráticas com o auxílio do software Wimplot}

Porém, para que isso ocorra é preciso que haja uma adequada escolha no tocante à escolha do software a ser utilizado. Também, que o professor tenha se apropriado de conhecimentos suficientes acerca do conteúdo a ser trabalhado, e o domínio das ferramentas disponibilizadas no referido software e que atendam às necessidades de facilitar o diálogo homem-máquina, com o propósito de contribuir para a apropriação do conhecimento.

Existem propostas para o trabalho nas aulas de Matemática que privilegiam tanto o diálogo quanto a participação ativa dos estudantes e do professor, possibilitando que os alunos tornem-se sujeitos e não objetos - tanto na apropriação e produção de conhecimentos matemáticos, quanto na aquisição de habilidades e competências requeridas para tal. Destacaremos, aqui, a abordagem investigativa, como uma alternativa ao ensino tradicional de Matemática na Escola Básica.

Lerman (1996) defende que é imprescindível a utilização de atividades investigativas nas aulas de matemática, pois entende que os processos desenvolvidos nas aulas dessa disciplina não podem ser desprestigiados com uma excessiva valorização dos conteúdos.

Segundo Lerman (1996, p. 142), “aulas centradas em conteúdos promovem muitas destrezas e técnicas, porém não valorizam o ato de pensar matematicamente".

Segue um exemplo pessoal, relatado por Lerman (1996), que ilustra o seu posicionamento: Lerman (1996, p.145), conta ter recebido um convite para integrar uma equipe de cientistas com o objetivo de produzir um modelo matemático que representasse a poluição de um lago. Não diz qual era o lago, mas afirma que o mesmo era importante. Prossegue no seu relato, dizendo ter recusado o convite pois não havia estudado Modelos Matemáticos de Lagos na Universidade. Ele explica ter declinado do convite, pois naquele momento de sua vida não se considerava “capaz de fazer matemática de forma criativa, mas sim apenas recordar e reproduzir, razoavelmente, aquilo que lhe havia sido ensinado".

Lerman (1996) utiliza esta experiência pessoal para defender as investigações matemáticas na sala de aula. Para ele, possibilitar aos alunos situações em que possam utilizar a matemática para investigar - desde situações puramente matemáticas, até situações envolvendo problemas sociais - é uma prática mais adequada do que simplesmente ensinar conteúdos. Lerman (1996, p.143) entende que quando o professor oferece aos alunos a oportunidade de se engajarem em uma atividade investigativa "coloca uma ferramenta poderosa nas mãos dos indivíduos para analisarem o que se passa nas suas vidas, oferecendo-lhes a oportunidade de a alterarem".

Tangram - Revista de Educação Matemática, Dourados - MS - v.2 n.4, pp. 58 - 78 (2019) 


\section{Funções Quadráticas com o auxílio do software Wimplot}

Alro e Skovsmose (2006) denominam abordagens investigativas como um conjunto de propostas pedagógicas que, segundo eles, desafiam as aulas de matemática ambientadas no paradigma do exercício² ${ }^{2}$.

Em uma atividade investigativa o aluno trabalha como um pesquisador, no sentido de tentar compreender o problema colocado e encontrar a(s) solução(ões), sem seguir um modelo pré-estabelecido. Dentre as abordagens investigativas estão as relacionadas à resolução de problemas; o trabalho com projetos; a modelagem matemática etc. Para estes pesquisadores, uma atividade investigativa pode contribuir muito mais com a aprendizagem dos alunos do que a resolução de inúmeros exercícios com um mesmo padrão de solução que geralmente é explicado por meio de um exemplo apresentado pelo professor.

Segundo Skovsmose (2000), propor cenários para a investigação em sala de aula pode contribuir para o envolvimento dos alunos na compreensão de uma determinada situação. Mas, para isso, é preciso que tal proposição fique claro para os alunos e desde que eles aceitem o convite para mergulharem na investigação em questão.

Ao se referir ao currículo como uma estratégia de ação educativa, Skovsmose (2000) se apropria das ideias de Freire (1996), apud D'Ambrosio (2005), sobre literacia ${ }^{3}$, e propõe que se privilegie o desenvolvimento da materacia ${ }^{4}$ em aulas de matemática.

Os alunos têm menos possibilidades de desenvolver essa competência em um ambiente tradicional de ensino, pois segundo Skovsmose (2000, p.68) "a materacia não se refere apenas às habilidades matemáticas mas também à competência de interpretar e agir numa situação social e política estruturada pela matemática". Para o autor, a preocupação do professor em desenvolver essa competência possibilita, no ambiente de sala de aula, uma reflexão crítica sobre a utilização social da matemática.

Tanto Skovsmose (2000) quanto Ponte, Brocardo e Oliveira (2003) observam que através de atividades investigativas, os alunos podem construir conhecimentos matemáticos. Assim, os papéis do professor e dos alunos não são os mesmos que os que são atribuídos a ambos em uma aula apresentada segundo o estilo tradicional de ensino.

\footnotetext{
${ }^{2} \mathrm{O}$ paradigma do exercício se refere à situação em que o professor transmite informações e os alunos resolvem exercícios, seguindo os modelos ensinados.

3 A literacia é a capacidade de processar informação escrita ou falada, o que inclui leitura, escritura, cálculo, diálogo, ecálogo, mídia, internet na vida cotidiana (instrumentos comunicativos) D’Ambrosio (2015, p. 119). 4 A materacia é a capacidade de interpretar e analisar sinais e códigos, de propor e utilizar modelos e simulações na vida cotidiana, de elaborar abstrações sobre representações do real (instrumentos intelectuais) D'Ambrosio (2015, p. 119).
}

Tangram - Revista de Educação Matemática, Dourados - MS - v.2 n.4, pp. 58 - 78 (2019) 


\section{Funções Quadráticas com o auxílio do software Wimplot}

Nas aulas com o uso de atividades investigativas, o professor propõe diferentes cenários de investigação e orienta os alunos quanto às suas dificuldades. Ao aceitarem tal proposta os alunos assumem a responsabilidade de investigar e de procurar 1(uma) ou mais soluções à situação-problema posta em discussão/solução, atuando de modo mais autônomo para os possíveis questionamentos acerca da problemática envolvida. Podem, inclusive, levantar hipóteses e/ou argumentar com mais desenvoltura em relação aos problemas que estariam sendo investigados. Talvez por isso, as Diretrizes Curriculares Nacionais para os Cursos de Licenciatura em Matemática presentes em Brasil $(2001,2002)$, quando referem à utilização de recursos tecnológicos, recomendam que desde o início do curso de graduação o licenciando deve adquirir familiaridade com o uso do computador como instrumento de estudo, trabalho e pesquisa. Os autores do Parecer CNE/CES 1302/2001, em Brasil (2001), assim referem no tocante à essa questão:

Desde o início do curso e licenciando deve adquirir familiaridade com o uso do computador como instrumento de trabalho, incentivando-se sua utilização para o ensino de matemática, em especial para a formulação e solução de problemas. É importante também a familiarização do licenciando, ao longo do curso, com outras tecnologias que possam contribuir para o ensino de Matemática (Brasil, 2001, p.6).

Com o propósito de pesquisar causas e efeitos dos conhecimentos dos professores no rendimento dos alunos, Shulman (1986) encaminhou pesquisas que tinham o propósito de responder questões tais como: O que ensinar? Como ensinar? no tocante aos conhecimentos necessários à docência, dos professores em serviço.

São conhecimentos, na prática docente, que têm relação direta sobre o que os professores pensam quando ensinam. Ou seja, referem-se aos conhecimentos de conteúdo, conhecimentos pedagógicos de conteúdo e conhecimentos curriculares, os quais interagem entre si por meio dos saberes dos professores, isto é, são constituintes do domínio do professor para desenvolver diferentes aspectos que envolvem a docência.

Á época Shulman (1986) classificou 7(sete) categorias de conhecimentos, mas as agrupou nas 3(três) que foram listadas acima. Não obstante Shulman(1986) não ter desconsiderado situações de aprendizagem que envolvem o domínio e o uso de tecnologias digitais, quando empreendeu as pesquisas sobre as bases de conhecimentos necessários à docência, a rápida evolução tecnológica fez com que mudanças na escola e nas ações pedagógicas dos professores tornassem-nas rapidamente substituíveis, o que fez com que os

Tangram - Revista de Educação Matemática, Dourados - MS - v.2 n.4, pp. 58 - 78 (2019) 


\section{Funções Quadráticas com o auxílio do software Wimplot}

professores não apenas tivessem que se preocupar com o domínio das ferramentas disponíveis à época mas preocupações de como ensinar, com o uso delas em sala de aula.

Por conta disso e com o propósito de ampliar os conhecimentos abordados por Shulman (1986) a respeito do conhecimento matemático para o ensino ${ }^{5}$, pesquisadores como Ball; Thames e Phelps (2008) propuseram pesquisas acerca do componente conhecimento tecnológico (TK), com repartição em 2(duas) vertentes: conhecimento pedagógico tecnológico (TPK) e conhecimento tecnológico do conteúdo (TCK).

\section{Os sujeitos do estudo}

O estudo envolveu a formação de 2(dois) alunos de 15 anos de idade que à época do estudo cursavam a $1^{\mathrm{a}}$ série do ensino médio, e 2(dois) professores que ensinavam matemática em turmas do Ensino Fundamental. Todos os quatro, doravante chamados de sujeitos do estudo, à época do estudo pertenciam a uma Rede Estadual de Ensino em uma grande cidade, capital do estado. Os professores foram convidados pelo pesquisador, autor deste artigo e estes convidaram seus ex-alunos do $9^{\circ}$ Ano do Ensino Fundamental. Segundo os professores que os convidaram a escolha deu-se em razão de eles terem sido seus alunos, terem estudado o conteúdo Funções Quadráticas por meio de lápis e papel, segundo uma abordagem tradicional (exposição do conteúdo no quadro branco, e em seguida a resolução de exercícios do livro didático); serem alunos responsáveis, dedicados; terem tido bom aproveitamento na resolução dos exercícios e com bons resultados nas avaliações. Portanto, segundo eles, em condições de oferecerem contribuições para possíveis melhorias à proposta de atividades objeto do estudo. O grupo como um todo, formado por 2(dois) professores em uma dupla, e 2(dois) alunos em outra dupla, esteve presente em todos os 3(três) encontros objeto do estudo. Cada encontro teve duração média de 3(três) horas cada, realizado na própria escola dos sujeitos de estudo em turno oposto ao de aulas dos alunos, em uma sala de informática que estava disponível para a realização das atividades, previamente reservada para tal na $3^{\text {a }}$, $4^{\mathrm{a}}$ e $5^{\mathrm{a}}$ feira daquela semana.

\section{O tipo de estudo}

5 No texto original, conhecimento matemático para o ensino está escrito Mathematical Knowledge for Teaching, daí MKT.

Tangram - Revista de Educação Matemática, Dourados - MS - v.2 n.4, pp. 58 - 78 (2019) 


\section{Funções Quadráticas com o auxílio do software Wimplot}

A investigação reuniu forte cunho descritivo, incluindo os diálogos havidos no lócus dos sujeitos do estudo - eles entre si, e com o pesquisador - ao longo de uma sequência de 3(três) encontros de estudo com duração, aproximada, de 3(três) hora em cada.

O pesquisador procurou estar atento a todos os elementos presentes nas situações estudadas, sabendo de antemão que aspectos por vezes considerados triviais e aparentemente considerados sem importância podem se transformar em informações valiosas para compor o conjunto de dados do estudo. Portanto, aspectos carregados de significados, que ajudam na compreensão dos fenômenos em questão.

Assim, considerando alguns aspectos básicos que caracterizam uma investigação qualitativa, como os presentes em Lüdke e André (1986, p.9), considerou-se que o estudo se caracterizou como uma "investigação de natureza qualitativa". Por sua vez, o estudo foi desenvolvido em um ambiente natural (sala de aula), para a coleta direta dos dados, onde o pesquisador exerceu papéis que o colocaram como o instrumento central para tal. Nesse ambiente, o pesquisador não se valeu do propósito de recriar experimentalmente questões de estudo que não as que foram propostas no início do trabalho investigativo, e sobre as quais se propôs a estudar, observar e coletar dados de estudo.

\section{O software no estudo de Funções Quadráticas}

Os softwares Winplot, Graphmática e Geogebra têm sido amplamente utilizados no estudo de aspectos qualitativos e quantitativos relacionados à temática funções. O software Winplot é um software gratuito, de autoria de Richard Parris, e foi traduzido para o português (do Brasil), pelo professor Adelmo Ribeiro de Jesus, do Departamento de Matemática da UFBA - Universidade Federal da Bahia. Trata-se de um programa gráfico, de propósito geral, que permite o traçado e a animação de gráficos em 2D e em 3D por meio da utilização de diversos tipos de equações. Tal software permite promover animação de gráficos a partir de parâmetros adotados. O software Winplot traça simultaneamente os gráficos de famílias de funções, por exemplo. A palavra que constitui o seu nome: WIN + PLOT o define como um programa para plotar gráficos de funções matemáticas de 1(uma) ou 2(duas) variáveis utilizando a plataforma do Windows. O software Winplot contribui para despertar o interesse do usuário, promover a aprendizagem e favorecer a construção do conhecimento. Esses são os motivos pelos quais foi feita a opção por utilizá-lo para desenvolver as atividades

Tangram - Revista de Educação Matemática, Dourados - MS - v.2 n.4, pp. 58 - 78 (2019) 


\section{Funções Quadráticas com o auxílio do software Wimplot}

relacionadas com a construção, exploração e análises de gráficos de funções quadráticas integrando-o às ideias presentes na Modelagem Matemática (ramo de pesquisa da Matemática Aplicada).

\section{Objetivos adotados quando do desenho inicial}

Por conta do desenho inicial da proposta objeto deste estudo, conforme a metodologia de Design Experiments in Educational Research, estabeleceu-se os objetivos gerais e específicos, como descritos a seguir.Os objetivos gerais do estudo foram os de:

- Explorar alguns dentre os diferentes comandos do software Winplot;

- Desenvolver atividades de matemática, utilizando comandos do software Winplot;

- Verificar a aplicabilidade do software, com o seu uso, no sentido de avaliar possibilidades de utilizá-lo em outros conteúdos da Matemática - tanto no Ensino Fundamental quanto no Ensino Médio;

- Verificar a aplicabilidade do software, com o seu uso, envolvendo conteúdos de matemática indicados para serem ensinados a alunos do Ensino Médio e a possibilidade do seu uso, integrado não apenas com o aspecto exploratório mas também o investigativo;

- Refletir e discutir sobre as potencialidades do Winplot para a resolução de atividades investigativas em aulas de Matemática;

- Refletir e discutir em relação à adaptação e elaboração de atividades em harmonia com a apropriação do conhecimento matemático, pelos alunos e professores;

- Identificar e promover mecanismos motivacionais para os alunos e professores no tocante ao uso de tecnologia durante a resolução de problemas;

- Estabelecer condições favoráveis aos professores no sentido de diminuir ou estancar a preocupação em motivar os alunos para o uso de tecnologia na resolução de problemas;

- Identificar ferramentas necessárias à gestão da sala de aula por meio do oferecimento de atividades investigativas fazendo uso de tecnologia;

Tangram - Revista de Educação Matemática, Dourados - MS - v.2 n.4, pp. 58 - 78 (2019) 


\section{Funções Quadráticas com o auxílio do software Wimplot}

- Diminuir ou estancar a preocupação de alunos e professores quanto à viabilidade de uso de tecnologia como instrumento pedagógico facilitador da aprendizagem e, por fim,

- Oportunizar que o professor reflita sobre a própria prática, quando da utilização de metodologia investigativa diferenciada.

Portanto, de modo geral, o objetivo principal é o de mostrar aos participantes as reais possibilidades do uso de um software (não, necessariamente, o Winplot) com o objetivo de facilitar a compreensão dos alunos com respeito à apropriação dos conceitos e o domínio de procedimentos necessários à compreensão dos significados destes.

Segundo Fagundes (2004, p. 25), "é fundamental que a preparação de professores para o uso de tecnologias ofereça a estes experiências de aprendizagem com as mesmas características das que deverão proporcionar aos alunos".

Os objetivos específicos do estudo foram os seguintes:

- Verificar a aplicabilidade do software, com o seu uso, no sentido de atender às necessidades de utilização no conteúdo de funções quadráticas em diferentes atividades de investigação e de resolução de problemas;

- Em particular, identificar facilidades na resolução de problemas com equações e inequações do $2^{\circ}$ grau e, simultaneamente, verificar a viabilidade de propor atividades semelhantes (e outras) em turmas regulares, com alunos do $9^{\circ}$ Ano do Ensino Fundamental.

\section{Metodologia do estudo}

Foi adotada a metodologia de Design Experiments in Educational Research, de Cobb et al (2003). A escolha se deu por conta dessa metodologia permitir uma flexibilidade para adaptar o desenho inicialmente proposto para o desenvolvimento das diferentes atividades que serão propostas, levando em conta a produção (aproveitamento) apresentada pelos sujeitos do estudo, em momentos não previamente determinados. Desse modo o desenho é preliminarmente elaborado e fica sujeito a remodelações, reformulações, em idas e vindas, as quais permitem que, por conta disso, se possa fazer novas conjecturas e novas perguntas de estudo, a qualquer tempo, que devem ser testadas a posteriori.

Por essas razões, as análises são feitas nos sujeitos do estudo, na análise das suas trajetórias, na coleta das dificuldades, facilidades e nos avanços obtidos. Ou seja, é previsto Tangram - Revista de Educação Matemática, Dourados - MS - v.2 n.4, pp. 58 - 78 (2019) 


\section{Funções Quadráticas com o auxílio do software Wimplot}

elaborar experimentos de ensino de conceitos e procedimentos da Matemática com o propósito de obter inovações diversas mediante avanços obtidos pelos sujeitos do estudo. Sendo assim, trata-se de um processo amplo, flexível, cíclico, iterativo e ajustável.

$\mathrm{O}$ fato de tal escolha recair sobre essa metodologia visou atender os propósitos relacionados à obtenção de respostas para a questão de estudo. Eis, então, os propósitos:

- Definição de documentos diagnósticos e a elaboração de questões para compor as fichas de atividades de modo a conhecer aspectos do conhecimento matemático e do uso de tecnologia presentes nas ações dos sujeitos do estudo;

- Conhecer as experiências docentes com o uso de tecnologias que os professores traziam àqueles momentos, acerca dos conhecimentos defendidos por Shulman (1986) quanto às respectivas formações em serviço, aos conhecimentos de conteúdo e aos conhecimentos pedagógicos de conteúdo;

- Avaliar como se deu a elaboração e a aplicação das 3(três) fichas de atividades, integrantes da sequência didática, no tocante à viabilidade, abrangência, adequação e efetividade;

- Promover a resolução das questões de conteúdo matemático propostas e, com ela, propor reflexões e discussões de todo o grupo - primeiramente, no seio de cada dupla, e depois com os quatro sujeitos de estudo e o pesquisador -, no tocante à conhecer possibilidades para (re) significar os conhecimentos dos professores no que refere às atividades docentes relacionadas com a apropriação de conceitos, procedimentos e competências do conteúdo com o auxílio de tecnologia.

- Propor e desenvolver as atividades presentes nas fichas de atividades, e outras que viessem a ser propostas pelos sujeitos de estudo, quando da apresentação, desenvolvimento e resolução de problemas associados com o conteúdo em questão com alunos, em turmas regulares, próprios à avaliar possibilidades de ampliar a visão conceitual de todos os envolvidos.

Dentre os diferentes modos de aplicação da metodologia Design Experiments in Educational Research para o presente estudo, selecionou-se o modelo de pequena escala, o qual se aplica a um pequeno grupo de sujeitos de pesquisa, visando analisar em detalhes as suas trajetórias, a ambiência da proposta e a necessidade ou não de adequação quando aplicado em escala maior. Para esse estudo preliminar o pesquisador assumiu diferentes Tangram - Revista de Educação Matemática, Dourados - MS - v.2 n.4, pp. 58 - 78 (2019) 


\section{Funções Quadráticas com o auxílio do software Wimplot}

papéis, a saber: professor, orientador, interventor e pesquisador. Assim, interviu principalmente em situações que envolviam o bloqueio dos sujeitos do estudo frente à dificuldades (ou impossibilidade) de prosseguirem, para realizarem o que era pedido nas atividades propostas nas fichas de atividades.

Nesse sentido, coube ao pesquisador o trabalho de identificar se haveria ou não necessidade de serem feitas adaptações no desenho inicial - as quais foram avaliadas e julgadas tanto por si quanto pelos sujeitos do estudo nos momentos em que tais impasses ocorriam. Tais ações, tiveram o propósito de, rapidamente, decidir quanto à viabilidade da aplicação/execução/desenvolvimento do desenho inicial (ou modificado) com alunos do $9^{\circ}$ Ano do Ensino Fundamental em uma turma regular tal qual como planejado inicialmente, ou testar hipóteses que viessem a ser levantadas durante o desenrolar das atividades.

O estudo foi proposto com o propósito de avaliar o desenvolvimento da sequência de atividades objeto de 3(três) fichas de atividades, no sentido de que os sujeitos do estudo tivessem a liberdade de concordar, discordar e/ou sugerir modificações, acréscimos ou retiradas no tocante às atividades constantes das fichas de atividades que estavam sendo propostas e outras que, eventualmente, viessem a surgir.

Portanto, tais atividades seriam avaliadas e reavaliadas durante e após os encontros. Isto é, seriam objeto de avaliação ao desenho preliminar proposto com o propósito de, uma vez tivessem sido consideradas consistentes do ponto de vista metodológico e pedagógico, mais adiante pudesse constituir uma proposta efetiva de ensino que pudesse ser aplicada a alunos de turmas regulares do $9^{\circ}$ Ano do Ensino Fundamental.

\section{Conteúdo das Fichas de Atividades propostas aos sujeitos do estudo}

O desenho inicial propôs a preparação de 3(três) Fichas de Atividades, que conteriam atividades e problemas que seriam resolvidos pelos sujeitos de estudo, com o auxílio do software Winplot, para mostrar o gráfico de 1(uma) ou mais funções quadráticas em um mesmo sistema cartesiano ortogonal e representado em uma malha quadrangular. A seguir, apresentam-se todas atividades que foram desenvolvidas pelos sujeitos do estudo, ao longo de 3(três) encontros:

Ficha de Atividades 1:

Num mesmo par de eixos cartesianos ortogonais plote os gráficos das funções:

Tangram - Revista de Educação Matemática, Dourados - MS - v.2 n.4, pp. 58 - 78 (2019) 


\section{Funções Quadráticas com o auxílio do software Wimplot}

$\mathrm{f}(\mathrm{x})=\mathrm{y}=\mathrm{x}^{2}, \mathrm{~h}(\mathrm{x})=\mathrm{y}=(\mathrm{x}-1)^{2}, \mathrm{j}(\mathrm{x})=\mathrm{y}=(\mathrm{x}-5)^{2}, \mathrm{~m}(\mathrm{x})=\mathrm{y}=(\mathrm{x}-1 / 2)^{2} \mathrm{e} \mathrm{p}(\mathrm{x})=\mathrm{y}=$ $(\mathrm{x}-2 / 3)^{2}$. Sugestão: cada gráfico deve ser plotado em uma cor diferente dos demais.

Em seguida, responda e proceda conforme é pedido:

(a) Descreva o que acontece com o gráfico da função inicial, quando subtraímos uma constante real positiva da variável independente $\mathrm{x}$, mantendo o registro algébrico da função original: elevado ao quadrado;

(b) Em relação às 5(cinco) funções reais, presentes no item (a), identifique quais possuem zero real (raiz(es) real(is) para y $=0$ ). Qualquer função quadrática possui ao menos 1(um) zero? Explique.;

(c) Para cada função que possui zero, conforme as respostas apresentadas ao item (b), indique quantos e quais são os zeros, em cada caso;

(d) Compare o(s) valor(es) do(s) zero(s) de cada função com as respectivas representações algébricas. O que você observou?;

(e) Em um mesmo par de eixos cartesianos ortogonais plote os gráficos das funções $y=(x-2)^{2}$ e $y=(x-1 / 2)^{2}$. Em seguida, resolva a equação $(x-2)^{2}=(x-1 / 2)^{2}$ de 2 (dois) modos: resolvendo a equação via métodos algébricos e, em seguida, fazendo uso dos gráficos das 2(duas) funções, e já plotados. Descreva o que você fez para obter a(s) solução(ões) para essa equação por meio da análise gráfica;

(f) Em um mesmo par de eixos cartesianos ortogonais plote os gráficos das funções

$y=(x-5)^{2}$ e $y=(x-2 / 3)^{2}$. Em seguida, resolva a inequação $(x-5)^{2} \geq(x-2 / 3)^{2}$ fazendo uso dos gráficos das 2(duas) funções, e já plotados. Descreva o que você fez para obter a(s) solução(ões) para essa inequação por meio da análise gráfica;

Ficha de Atividades 2:

Num mesmo par de eixos cartesianos ortogonais, plote os gráficos das funções: $\mathrm{f}(\mathrm{x})$ $=\mathrm{y}=(\mathrm{x}-1)^{2}, \mathrm{~g}(\mathrm{x})=\mathrm{y}=2(\mathrm{x}-1)^{2} \mathrm{e} \mathrm{h}(\mathrm{x})=\mathrm{y}=4(\mathrm{x}-1)^{2}$. Sugestão: cada gráfico deve ser plotado em uma cor diferente dos demais. Em seguida, responda e proceda conforme pedido.

(a) Analisando os gráficos das 3(três) funções: $f(x), g(x)$ e $h(x)$, descreva o que você considera ser possível concluir em relação às similaridades presentes nos referidos gráficos;

(b) Tomando, a cada vez, 2(dois) dentre os 3(três) gráficos das funções f, g e h, verifique se eles têm 1(um) ou mais pontos em comum. Caso exista(m) ponto(s) em comum a cada 2(dois) gráficos analisados, por vez, determine as respectivas coordenadas desse(s) ponto(s);

Tangram - Revista de Educação Matemática, Dourados - MS - v.2 n.4, pp. 58 - 78 (2019) 


\section{Funções Quadráticas com o auxílio do software Wimplot}

(c) E quando ocorrer a análise em relação à existência ou não de ponto(s) em comum em relação aos 3(três) gráficos, em conjunto, eles têm 1(um) ou mais pontos em comum? Caso exista(m) ponto(s) em comum nos 3(três) gráficos analisados, por vez, determine as respectivas coordenadas desse(s) ponto(s).

Ficha de Atividades 3:

Em um mesmo par de eixos cartesianos ortogonais, plote o gráfico da função $\mathrm{f}(\mathrm{x})=$ $(\mathrm{x}+1)^{2}-1$. Para tal, siga os seguintes procedimentos:

(a) Primeiramente, plote o gráfico da função $f 1(x)=x^{2}$;

(b) No mesmo par de eixos cartesianos ortogonais, e mantendo o gráfico da função $\mathrm{f} 1(\mathrm{x})=\mathrm{x}^{2}$ plotado, plote o gráfico da função $\mathrm{f}_{1}(\mathrm{x})=\mathrm{y}=(\mathrm{x}+1)^{2}$;

(c) Observe os 2(dois) gráficos: de $\mathrm{f}$ e de $\mathrm{f}_{1}$, e responda: o que é preciso fazer com o gráfico da função f para obter o gráfico da função $\mathrm{f}_{1}$, caso você estivesse apenas com lápis e papel à mão?

(d) No mesmo par de eixos cartesianos ortogonais, e mantendo os gráficos da funções $\mathrm{f}(\mathrm{x})=\mathrm{x}^{2}$ e $\mathrm{f}_{1}(\mathrm{x})=(\mathrm{x}+1)^{2}$ plotados, plote o gráfico da função $\mathrm{f}_{2}(\mathrm{x})=\mathrm{y}=(\mathrm{x}+1)^{2}-1$;

(e) Explique como é possível desenhar o gráfico da função $f_{3}$ com lápis e papel a partir do gráfico da função $f_{2}$. Analise a sequência de gráficos das 3(três) funções que foram obtidos com a construção dos referidos gráficos um a seguir do outro. O que é possível constatar a esse respeito?;

(f) Você consegue prever de que forma será o gráfico da função $\mathrm{f}_{4}(\mathrm{x})=\mathrm{x}^{2}+2$, antes de desenhá-lo com lápis e papel? Explique;

(g) Agora, plote o gráfico da função $\mathrm{f}_{3}(\mathrm{x})=\mathrm{x}^{2}+2$;

(h) Analise a resposta que você apresentou para o item (f), à luz do gráfico de $f_{3}$ e, se necessário complemente a sua explicação apresentada no item (f) de modo que fique claro o que foi feito por você, como foi feito e a conclusão que é possível apresentar a esse respeito.

\section{Desenvolvimento das atividades e análise dos resultados obtidos}

O desenho inicial da proposta de estudo objeto deste trabalho contemplou 4(quatro) distintos momentos, que se complementam com o propósito de responder às questões iniciais apresentadas como determinantes para este estudo, que detalhamos em seguida.

Assim, de início, em um primeiro momento, foram realizadas atividades de reconhecimento do software Winplot, o qual foi previamente instalado nas 2(duas) máquinas Tangram - Revista de Educação Matemática, Dourados - MS - v.2 n.4, pp. 58 - 78 (2019) 


\section{Funções Quadráticas com o auxílio do software Wimplot}

usadas pelos sujeitos de estudo. Em um segundo momento foram realizadas atividades visando à construção de conhecimentos matemáticos, cujo objetivo foi o de permitir que os sujeitos do estudo conhecessem o software Winplot e suas reais possibilidades de uso em situações de aprendizagem semelhantes às que seriam vivenciadas em prosseguimento.

Neste momento, e de maneira breve, o pesquisador expôs algumas ideias acerca de diferentes tecnologias utilizadas em Educação Matemática; o conceito de software livre e a importância de tratar dessas questões na Educação Básica, tanta para contribuir para melhorar a formação continuada do professor que ensina Matemática neste segmento de ensino quanto para a reflexão de todos: alunos e professores, a respeito da importância de seu uso como complementação ao estudo tradicional via lápis, papel e quadro branco. Esses dois primeiros momentos teve a duração, aproximada, de 1(uma) hora. Em um terceiro momento o pesquisador entregou a $1^{\mathrm{a}}$ Ficha de Atividades aos sujeitos do estudo, e fez comentários a respeito das atividades que seriam propostas nela e nas outras 2(duas), que seriam distribuídas em prosseguimento. Salientou que todas as atividades contariam com a utilização do software Winplot, de modo a oportunizar ampliação conceitual relativa aos conceitos pertinentes ao conteúdo de funções quadráticas, tais como: uma breve introdução a respeito dos principais comandos do software Winplot, seguida de breve discussão a respeito de noções intuitivas de funções. Esse terceiro momento teve a duração, aproximada, de 40 minutos, após o qual deu-se início à aplicação da Ficha de Atividades 1.

Em um quarto momento o pesquisador se debruçou em organizar os dados coletados ao longo dos 3(três) encontros, segundo anotações pessoais e o conteúdo apresentado pelos sujeitos do estudo nas 12 fichas de atividades - 4(quatro) fichas por encontro) - entregues ao final de cada encontro. Assim, o pesquisador pode analisar os dados coletados e refletir sobre o desenrolar das atividades à luz da literatura disponível acerca da temática, e do seu conhecimento, com o propósito de construir pistas norteadoras para um estudo mais abrangente em Educação Matemática. Estudo acerca das possibilidades de ensino e aprendizagem da temática por meio de tecnologia disponível para uso tanto dos professores quanto dos alunos, e a implicação que o uso de tecnologias acarreta em relação à melhoria da formação de professores que ensinam Matemática e o aprendizado dos alunos, em estreita correspondência.

Uma vez que nova proposta de estudo leve em conta as análises feitas com base nesse estudo e nos resultados que foram obtidos para esse particular universo de sujeitos de estudo

Tangram - Revista de Educação Matemática, Dourados - MS - v.2 n.4, pp. 58 - 78 (2019) 


\section{Funções Quadráticas com o auxílio do software Wimplot}

envolvidos, objeto deste trabalho, é preciso aprofundar questões pertinentes aos conhecimentos dos professores, tanto na perspectiva de Shulman (1986) quanto na perspectiva de Ball; Thames e Phelps (2008) no tocante ao conteúdo que foi abordado; os conhecimentos necessários ao professor para encaminhar as situações de aprendizagem, e quanto ao teor e abrangência das atividades que foram propostas nas fichas de atividades com vista à melhoria do ensino que tem sido ofertado aos alunos da escola básica.

Assim, a partir desse estudo e da avaliação em relação à utilização e a análise das potencialidades desse software, se pode afirmar que ele contribui para o desenvolvimento da capacidade de observação, investigação e senso crítico do usuário, ao mesmo tempo que possibilita a associação de ideias relativas à construção de gráficos de funções quadráticas. Seu uso evita, assim, a simples memorização e imitação - muito presente em aulas que se assemelham ao estilo tradicional de ensino.

Consideramos que a resolução das atividades com o uso do software Winplot melhorou a compreensão dos sujeitos do estudo - fazendo um paralelo e referência ao estudo que habitualmente é feito com o uso de lápis e papel - no tocante à compreensão e facilidade com que eles encontraram o(s) zero(s) de uma função quadrática - quando este(s) existe(m).

Dentre as funções que foram objeto de estudo nas fichas de atividades, faltou apresentar pelo menos 1(uma) função que não possui zeros. Salienta-se que mostrarem-se produtivas as atividades de construção de gráficos de funções quadráticas derivadas da função $f(x)=x^{2}$, de modo a ampliar essas ideias para outros tipos de funções.

Porém, é preciso, ainda, que se trabalhe o conceito de que toda função quadrática pode ser escrita na forma de um produto, assim: $f(x)=a x^{2}+b x+c=a \cdot\left(x-x_{1}\right) \cdot\left(x-x_{2}\right)$, onde $\mathrm{x}_{1}$ e $\mathrm{x}_{2}$ são as raízes reais da equação $\mathrm{f}(\mathrm{x})=\mathrm{ax}^{2}+\mathrm{bx}+\mathrm{c}=0$. Também, um trabalho de fatoração de funções quadráticas e a relação com o correspondente esboço do gráfico.

Assim, considera-se que o estudo foi produtivo em relação ao que foi proposto mas carece de complementação de modo a atender conceitos presentes no universo das funções quadráticas: tanto no que diz respeito ao esboço de gráficos quanto aos relativos à resolução de inequações quadráticas.

\section{Considerações Finais}

Tangram - Revista de Educação Matemática, Dourados - MS - v.2 n.4, pp. 58 - 78 (2019) 


\section{Funções Quadráticas com o auxílio do software Wimplot}

Com esse trabalho, que integra o binômio Tecnologias Informáticas e Matemática, esperamos que o processo de inserção dos recursos tecnológicos nas escolas passe por mecanismos e dinâmicas de mudança que abrangem a prática do professor e a sua proposta pedagógica (conforme o projeto político-pedagógico estabelecido pela comunidade escolar), ao considerar a possibilidade de o professor desenvolver um sua prática pedagógica cotidiana o trabalho em ambientes informatizados, também.

Esses momentos possibilitam o surgimento de profissionais críticos e criativos, capazes de abordarem diferentes conceitos - por meio do uso de tecnologias diferenciadas que utilizem a experimentação e a investigação, contribuindo para o conhecimento, compreensão e apropriação acerca de variadas representações (gráficas e numéricas), bem como aponta para a necessidade de os professores refletirem e discutirem com os seus pares no dia a dia da sala de aula de Matemática na Educação Básica.

Esperamos que este trabalho contribua para que os leitores empenhem tempo, vontade e determinação para fazerem análises críticas acerca da viabilidade de propostas de trabalho semelhantes a essa serem oportunizadas aos seus alunos.

Ademais, também aponta para a possibilidade de proposição de pesquisas na área de formação inicial de professores e em formações continuadas de professores que ensinam Matemática na Educação Básica, levando em conta considerações sobre as potencialidades que há para o desenvolvimento de trabalhos similares, também em grupos de estudos.

Importante registrar que propostas de utilização da informática na educação e do uso de abordagens investigativas na aulas de matemática são oportunas, atraentes, benvindas e, por conta disso, não se esgotam no tempo. É propósito do autor que a experiência objeto deste trabalho ainda seja repicada algumas vezes, em menor escala.

Ou seja, possivelmente em um único encontro de até 4(quatro) horas, tanto para professores quanto para alunos, em grupos menores que o quantitativo de uma turma regular de alunos do ensino fundamental ou do ensino médio, quando, então, as atividades (algumas) devem ser propostas, resolvidas e discutidas com e pelos participantes.

Poder-se-á fazer uso do software Winplot ou não, vez que a escolha do software não modifica nem inviabiliza os propósitos metodológicos que estão por detrás da proposta de ensino da temática, em questão.

\section{Referências}

Tangram - Revista de Educação Matemática, Dourados - MS - v.2 n.4, pp. 58 - 78 (2019) 


\section{Funções Quadráticas com o auxílio do software Wimplot}

Almeida, Fernando José de, Fonseca Júnior, Fernando Moraes (2000). Aprendendo com Projetos. In: BRASIL, Ministério da Educação e do Desporto. Proinfo: projetos e ambientes inovadores. 96 p. (Série de Estudos. Educação a Distância, v. 14. Brasília: MEC, SEED.

Alro, Helle, Skovsmose, Ole (2006). Diálogo e Aprendizagem em Educação Matemática. Coleção Tendências em Educação Matemática. Tradução: Orlando Figueiredo. Belo Horizonte: Autêntica.

Ball, Deborah Loewenberg; Thames, Mark Hoover; Phelps, Geofrey Charles (2008). Content knowledge for teaching: What makes it special? Journal of Teacher Education. n. 59, p.389-407. Disponível em:

https://www.researchgate.net/publication/255647628_Content_Knowledge_for_Teach ing_What_Makes_It_Special Acesso em 01 de julho de 2019.

Brasil (2001). Ministério da Educação e do Desporto. Conselho Nacional de Educação. Parecer CNE/CES 1302/2001, aprovado em 06 de novembro de 2001. Estabelece as Diretrizes Curriculares Nacionais para os Cursos de Matemática, Bacharelado e Licenciatura. Disponível em: http://portal.mec.gov.br/cne/arquivos/pdf/CES13022.pdf Acesso em 01 de julho de 2019.

Brasil (2002). Ministério da Educação e do Desporto. Conselho Nacional de Educação. Resolução CNE/CES 3/2002, de 18 de fevereiro de 2003. Estabelece as Diretrizes Curriculares Nacionais para os Cursos de Matemática. Diário Oficial da União, Brasília, 25 de fevereiro de 2003. Seção 1, p. 13. Disponível em:

http://portal.mec.gov.br/cne/arquivos/pdf/ces032003.pdf Acesso em 01 de julho de 2019.

Brasil (2015). Ministério da Educação e do Desporto. Conselho Nacional de Educação. Conselho Pleno. Resolução n. 02, de 01 de julho de 2015. Estabelece as Diretrizes Curriculares Nacionais para a formação inicial em nível superior (cursos de licenciatura, cursos de formação pedagógica para graduados e cursos de segunda licenciatura) e para a formação continuada. Disponível em: http://portal.mec.gov.br/docman/agosto-2017pdf/70431-res-cne-cp-002-03072015-pdf/file Acesso em 01 de julho de 2019.

Cláudio, Dalcídio Moraes, Cunha, Márcia Loureiro da (2001). As novas tecnologias na formação de professores de matemática. In: Cury, H. N. (org.). Formação de professores de matemática: uma visão multifacetada. Porto Alegre: EDIPUCRS.

Cobb, Paul; Confrey, Jere; diSessa, Andrea; Lehrer, Richard; Schauble, Leona (2003). Design Experiments in Educational Research. American Educational Research Association. vol. 32. No. 1. pp. 9-13. jan/fev.

D'Ambrosio, Ubiratan (2005). Sociedade, cultura, matemática e seu ensino. Educação e Pesquisa. v. 31, n.1, p. 99-120, jan./abr. São Paulo. FE-USP.

Fagundes, Lea (2005). Podemos Vencer a Exclusão Digital. Revista Nova Escola 171, (2004), 24-26.

Tangram - Revista de Educação Matemática, Dourados - MS - v.2 n.4, pp. 58 - 78 (2019) 


\section{Funções Quadráticas com o auxílio do software Wimplot}

Freire, Paulo (1996). Pedagogia da autonomia: saberes necessários à prática educativa. Coleção Leitura. São Paulo: Paz e Terra.

Kenski, Vani Maria (2007). Educação e tecnologias: o novo ritmo da informação. 141 p. Campinas: Editora Papirus.

Lerman, Stephen (1996). Intersubjectivity in mathematics learning: A challenge to the radical constructivist paradigm? Journal for research in mathematics education. Vol. 27, n.2, p. 133-150.

Lüdke, Menga e André, Marli E.D.A (1986). Pesquisa em educação: abordagens qualitativas. 99 p. São Paulo: E.P.U.

Ponte, João Pedro da; Brocado, Joana; Oliveira, Hélia (2003). Investigações matemáticas na sala de aula. Belo Horizonte: Autêntica.

Shulman, Lee S. (1986). Those who understand: knowledge growth in teaching. Educational. v.15, n.2, p.4-14.

Skovsmose, Ole (2000). Cenários para investigação. Boletim de Educação Matemática. Rio Claro: UNESP.

Valente, José Armando (1995). Informática na educação: conformar ou contornar a escola. n. 24. Universidade Federal de Santa Catarina. Florianópolis: Perspectiva.

Enviado:14/07/2019

Aceito:14/10/2019

Tangram - Revista de Educação Matemática, Dourados - MS - v.2 n.4, pp. 58 - 78 (2019) 